International Journal of Current Advanced Research

ISSN: O: 2319-6475, ISSN: P: 2319 - 6505, Impact Factor: SJIF: 5.995

Available Online at www.journalijcar.org

Volume 6; Issue 4; April 2017; Page No. 3439-3443

DOI: http://dx.doi.org/10.24327/ijcar.2017.3443.0288

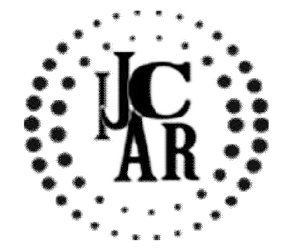

Research Article

\title{
PREVALENCE OF HYPOMAGNESAEMIA AND ITS CORRELATION WITH INSULIN RESISTANCE AND GLYCEMIC STATUS IN PATIENTS WITH TYPE 2 DM
}

\author{
Siba Prasad Dalai, Lalit Kumar Meher, Pankaj kumar Hui and Sameer Panda
}

Department of Medicine, MKCG Medical College

\begin{tabular}{l}
\hline A R T I C L E I N F O \\
\hline Article History: \\
Received $20^{\text {th }}$ January, 2017 \\
Received in revised form $19^{\text {th }}$ February, 2017 \\
Accepted $22^{\text {nd }}$ March, 2017 \\
Published online $28^{\text {th }}$ April, 2017 \\
\end{tabular}

Key words:

Hypomagnesaemia, insulin resistance, HOMAIR, QUICKI, diabetic retinopathy

\begin{abstract}
A B S T R A C T
Aim: To estimate the prevalence of hypomagnesaemia $\left(\mathrm{Mg}^{2+}<1.7 \mathrm{mg} / \mathrm{dl}\right)$ in patients with type $2 \mathrm{DM}$ and its correlation with insulin resistance and glycemic status.

Materials and Methods: 100 cases of type 2 diabetes mellitus fulfilling ADA criteria and 50 age and sex matched healthy controls presenting to a tertiary care hospital from October 2014 to September 2016 were included in our Case-Control study. Serum $\mathrm{Mg}^{++}$, fasting insulin, HbAlc along with other parameters were measured in all study subjects. Insulin resistance and sensitivity was calculated using the HOMA-IR model and QUICKI respectively.

Results: $34 \%$ of cases and $18 \%$ of controls had hypomagnesaemia. Prevalence of Hypomagnesaemia increased with the duration of diabetes. Patients with diabetic retinopathy had a significantly higher prevalence of hypomagnesaemia compared to those without retinopathy $(29 \%$ VS $5 \%) .23 \%$ of patients with $\mathrm{HbAlc}>7 \%$ had hypomagnesaemia as compared to $9 \%$ of patients with an $\mathrm{HbA1c}$ of $<7 \%$. A statistically significant inverse correlation was found between serum magnesium and HbAlc levels ( $\mathrm{r}=$ $-0.4395, \mathrm{P}<0.0001$ ). $21 \%$ of patients with Insulin resistance (HOMA-IR $>2.6$ ) had hypomagnesaemia whereas $12 \%$ of patients without Insulin resistance (HOMA-IR $<2.6$ ). The difference was significant. ( $\mathrm{P}$ value $=<0.0001$, $\mathrm{RR}=0.1092,95 \% \mathrm{CI}=0.6343$ 0.1879 ). A highly statistically significant inverse correlation was found between serum magnesium and HOMA-IR level $(\mathrm{r}=-0.6677, \mathrm{P}<0.0001)$. A statistically non-significant correlation was found between serum magnesium and HOMA- $\beta$. Logistic regression analysis showed fasting insulin levels, HbAlc levels and duration of diabetes to be independent predictors of hypomagnesaemia.

Conclusion: Prevalence of hypomagnesaemia was significantly more in diabetics and it increased with the duration of disease. Hypomagnesaemia contributed towards development of insulin resistance and impaired glycemic status in patients with type 2 diabetes.
\end{abstract}

Copyright $₫ 2017$ Siba Prasad Dalai et al. This is an open access article distributed under the Creative Commons Attribution License, which permits unrestricted use, distribution, and reproduction in any medium, provided the original work is properly cited.

\section{INTRODUCTION}

Magnesium $(\mathrm{Mg})$ is believed to play a pivotal role in glucose metabolism and insulin action. Diabetes mellitus have been suggested to be the most common metabolic disease associated with magnesium deficiency ${ }^{[1]}$. Hypomagnesaemia $(\mathrm{Mg}<1.7 \mathrm{mg} / \mathrm{dl})$ either latent or overt is commonly found in poorly controlled diabetes. Increased urinary loss and deficient dietary intake have been variably proposed as possible causes of hypomagnesaemia. Absorption deficits are rare ${ }^{[2]}$. Hyperglycemia and hyperinsulinemia increase urinary magnesium excretion by decreasing $\mathrm{Mg}$ tubular reabsorption [3]. Adequate glycemic control reduces urinary magnesium wasting ${ }^{[4]}$.

*Corresponding author: Siba Prasad Dalai

Department of Medicine, MKCG Medical College
$\mathrm{Mg}$ is a cofactor of almost all the rate limiting enzymes involved in glycolysis. It also plays an important role in regulation of insulin signaling, phosphorylation of tyrosine kinase, action of insulin at post receptor level and insulin mediated cellular glucose uptake ${ }^{[5,6]}$. Consequently hypomagnesaemia hampers all the above mechanisms contributing towards development of insulin resistance. Lower the basal intracellular $\mathrm{Mg}$, the greater the amount of insulin required to metabolize the same glucose load, indicating decreased insulin sensitivity ${ }^{[7]}$. Low intracellular concentrations of magnesium (and/ or elevated concentrations of calcium) may blunt insulin action and independently stimulates insulin secretion, leading to both hyperinsulinemia and insulin resistance concurrently ${ }^{[8]}$. There is high prevalence of hypomagnesaemia as well as Insulin resistance in type-2 diabetes mellitus in Indian population ${ }^{[9]}$. Hypomagnesaemia have been hypothesized both a cause and a consequence of various complications such as insulin 
resistance, dyslipidemia, atherosclerosis, hypertension and adverse pregnancy outcomes ${ }^{[10]}$. Some studies have also suggested that magnesium supplementation could be helpful in the treatment of diabetic patients by improving glycemic control and preventing the development of diabetes-related complications ${ }^{[11,12]}$.

Data in this field are scanty from our country ${ }^{[13,14]}$ and no such research work have been published from eastern India. The present study has been undertaken to estimate the prevalence of hypomagnesaemia in patients with type $2 \mathrm{DM}$ and its association and correlation with insulin resistance and glycemic status.

\section{MATERIALS AND METHODS}

A case control study was conducted at Department of Medicine after obtaining approval from Institutional Ethics Committee. 100 cases and age and sex matched 50 healthy controls were included in the study. Patients aged between 18 to 70 years fulfilling ADA criteria ${ }^{[15]}$ were included as cases. Patients with chronic kidney disease, hepatic dysfunction, acute myocardial infarction, other endocrine and rheumatologic diseases, chronic alcoholism, malabsorption, prolonged diarrhea, current malignancy, pregnant and lactating women, post-surgery, severe burns, patients on medications like lithium carbonate, magnesium and magnesium-containing antacids or laxatives, long term diuretic use ( $>6$ months) were excluded from our study.

Along with a detailed history and clinical examination, laboratory parameters were measured at the first contact including fasting and post prandial glucose, HbAlc, renal and liver function tests, fasting insulin levels, serum magnesium in all patients and controls. 12 lead ECG and fundoscopic examination was done in all subjects. Insulin resistance was calculated by using Homeostatic model assessment (HOMAIR) and insulin sensitivity by using quantitative insulin sensitivity check index (QUICKI) ${ }^{[16,17]}$.

HOMA-IR= fasting insulin $(\mu \mathrm{IU} / \mathrm{ml}) \times$ fasting glucose $(\mathrm{mg} / \mathrm{dl})$ $/ 405$

QUICKI=1 / ( $\log$ (fasting insulin $\mu \mathrm{U} / \mathrm{mL})+\log$ (fasting glucose $\mathrm{mg} / \mathrm{dL}$ )

Patients were considered as insulin resistant when, HOMA was $\geq 2.6$ and QUICKI was $\leq 0.337^{[18,19]}$.

\section{Statistical Analysis}

The data were analyzed by using SPSS software (version 20.0 for Windows). The results were expressed as a mean with $95 \%$ confidence limits or SD. A p-value of $<0.05$ was considered significant. Chi-square test was used to analyze the association between categorical variables. Pearson's correlation coefficient was used to describe continuous risk factors. An independent sample t-test was used for comparing two means variables that were normally distributed. Logistic regression analysis was used to determine the independent variables in the model.

\section{RESULTS}

Baseline characteristics of 100 cases and 50 controls was compared [Table-1]. Cases exhibited Insulin resistance as determined by a higher fasting insulin and HOMA-IR levels $(\mathrm{P}<0.0001)$ and a lower QUICKI $(\mathrm{P}<0.0001)$. Serum magnesium was significantly lower in cases as compared to controls $(\mathrm{P}=0.0308)$. Lipid profile and WHR and not BMI was significantly higher in cases as compared to controls.

Table 1 Baseline Characteristics and Metabolic Parameters of the Study Subjects

\begin{tabular}{|c|c|c|c|}
\hline VARIABLE & $\begin{array}{l}\text { CASE } \\
\mathbf{N}=100\end{array}$ & $\begin{array}{c}\text { CONTROL } \\
\mathbf{N}=\mathbf{5 0}\end{array}$ & $P$ value \\
\hline $\operatorname{SEX}(\mathrm{M} / \mathrm{F})$ & $50 / 50$ & $23 / 27$ & 0.7296 \\
\hline AGE (Years) & $51.13 \pm 10.034$ & $51.42 \pm 10.092$ & 0.8680 \\
\hline Duration of DM (Years) & $5.89 \pm 4.673$ & - & - \\
\hline $\mathrm{SBP}(\mathrm{mm} \mathrm{Hg})$ & $136.24 \pm 16.52$ & $125.52 \pm 10.96$ & $<0.0001$ \\
\hline $\mathrm{DBP}(\mathrm{mm} \mathrm{Hg})$ & $84.48 \pm 9.26$ & $74.52 \pm 8.57$ & $<0.0001$ \\
\hline BMI $\left(\mathrm{kg} / \mathrm{m}^{2}\right)$ & $23.17 \pm 4.782$ & $22.46 \pm 3.626$ & 0.3132 \\
\hline WHR & $0.8507 \pm 0.08$ & $0.812 \pm 0.054$ & 0.0006 \\
\hline $\mathrm{LDL}(\mathrm{mg} / \mathrm{dl})$ & $120.40 \pm 28.83$ & $106.98 \pm 20.2$ & 0.0012 \\
\hline $\mathrm{HDL}(\mathrm{mg} / \mathrm{dl})$ & $40.02 \pm 6.87$ & $37.64 \pm 4.84$ & 0.0154 \\
\hline TOTAL CHOL (mg/dl) & $209.54 \pm 56.23$ & $169.2 \pm 19.65$ & $<0.0001$ \\
\hline $\mathrm{TG}(\mathrm{mg} / \mathrm{dl})$ & $180.84 \pm 53.07$ & $150.4 \pm 29.09$ & $<0.0001$ \\
\hline $\operatorname{UREA}(\mathrm{mg} / \mathrm{dl})$ & $42.55 \pm 14.52$ & $38.68 \pm 9.9$ & 0.0572 \\
\hline Sr. Creatinine $(\mathrm{mg} / \mathrm{dl})$ & $1.46 \pm 3.77$ & $0.7 \pm 0.46$ & 0.0496 \\
\hline Sr. Sodium (meq/l) & $132.1 \pm 4.57$ & $131.42 \pm 3.726$ & 0.3316 \\
\hline Sr. Potassium (meq/l) & $3.7 \pm 0.7$ & $3.9 \pm 0.3$ & 0.0158 \\
\hline Sr. Magnesium (meq/1) & $1.76 \pm 0.495$ & $1.972 \pm 0.274$ & 0.0308 \\
\hline FBS (mg/dl) & $176.71 \pm 56.018$ & $96.2 \pm 5.47$ & $<0.0001$ \\
\hline PPBS (mg/dl) & $255.03 \pm 72.809$ & $155.36 \pm 17.57$ & $<0.0001$ \\
\hline HbA1c $(\%)$ & $8.75 \pm 1.666$ & $5.26 \pm 0.77$ & $<0.0001$ \\
\hline $\begin{array}{l}\text { FASTING INSULIN } \\
\qquad(\mu \mathrm{U} / \mathrm{ml})\end{array}$ & $14.21 \pm 10.158$ & $6.94 \pm 2.706$ & $<0.0001$ \\
\hline HOMA-IR & $2.30 \pm 1.806$ & $1.00 \pm 0.45$ & $<0.0001$ \\
\hline QUICKI & $0.3101 \pm 0.039$ & $0.358 \pm 0.022$ & $<0.0001$ \\
\hline НОМА- & $42.115 \pm 21.612$ & $76.902 \pm 16.880$ & $<0.0001$ \\
\hline
\end{tabular}

Mean \pm standard deviation for all parameters.

The mean age was $51.13 \pm 10.03$ years in cases and $51.42 \pm 10.09$ years in controls. The male to female ratio in the study group was $1: 1$ in cases and 1:1.17 in controls. The average duration of diabetes among the cases was $5.89 \pm 4.67$ years. $56 \%$ of the cases were having diabetes for 5 years duration, $30 \%$ for $6-10$ years and only $14 \%$ for more than 10 years. Hypertension was associated with $58 \%$ of the cases whereas Ischemic Heart Disease (IHD) was associated with $11 \%$ of cases. No associated comorbidities were found in $39 \%$ of cases included in the study population. The healthy controls were not associated with any comorbidities nor had diabetes at any point of time. In our study $68 \%$ of cases were taking some form of Oral hypoglycemic agents, 18\% were only on insulin therapy whereas $14 \%$ of cases were taking both OHA and Insulin. 35\% had retinopathy at the time of initial fundoscopy. $34 \%$ of cases and only $18 \%$ of controls had hypomagnesaemia.

\section{prevalence of hypomagnesaemia in cases and controls}

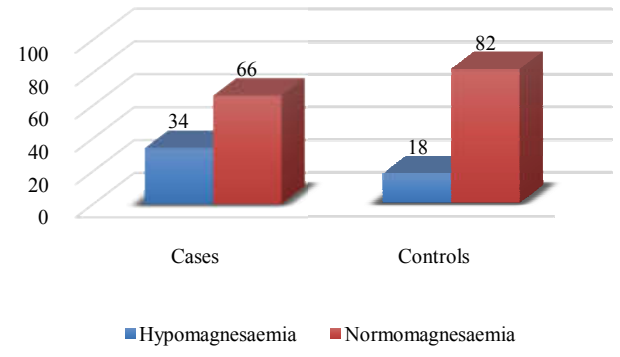

Figure 1 shows prevalence of hypomagnesaemia in study population: cases and controls. $34 \%$ of cases had hypomagnesaemia whereas only $18 \%$ of controls had hypomagnesaemia. The mean magnesium levels in cases was $1.76 \pm 0.495$ and in controls was found to be $1.972 \pm 0.274$, with a 2 -tailed p-value of 0.0308 which is considered significant. 
The mean magnesium levels in cases was $1.84 \pm 0.465$ and in controls was found to be $1.972 \pm 0.274$, with a 2-tailed pvalue of 0.0308 which is considered significant [Figure-1]. No significant differences were found in the rate of hypomagnesaemia in men and women in cases $(36 \%$ and $32 \%$ respectively) (Chi-square value $=0.044, \mathrm{P}=0.833, \mathrm{DF}=1$ ). Similarly the difference in rates of hypomagnesaemia in controls had no statistical significance $(20 \%$ and $16 \%$ respectively) (Chi-square value $=0.1355, \mathrm{P}=1.0, \mathrm{DF}=1) \mathrm{A}$ higher prevalence of hypomagnesaemia was observed in patients treated with insulin as compared to oral hypoglycemic agents (OHA). (16\% for Insulin vs $8 \%$ for OHA). The difference was statistically significant. As duration of diabetes increased from $<5$ years to 5-10 years, the prevalence of hypomagnesaemia increased from $7 \%$ to $56.6 \%$ which further increased to $92.85 \%$ in $>10$ years duration of diabetes. Prevalence of Hypomagnesaemia increased with the duration of diabetes.

Patients with diabetic retinopathy had a significantly higher prevalence of hypomagnesaemia compared to those without retinopathy (29\% VS 5\%). The difference was statistically significant. (Chi-square value $=52.97, \mathrm{P}$ value $<0.0001$, at degree of freedom=1). $76.9 \%$ cases of NPDR were having hypomagnesaemia, whereas all cases of PDR had hypomagnesaemia at the time of presentation. $92.3 \%$ cases without any evidence of retinopathy during fundoscopy were normomagnesaemic.

$23 \%$ of patients with $\mathrm{HbA} 1 \mathrm{c}>7 \%$ had hypomagnesaemia as compared to $9 \%$ of patients with an $\mathrm{HbAlc}$ of $<7 \%$. The difference was just significant. $(\mathrm{P}$ value $=0.0153, \mathrm{RR}=$ $0.4706,95 \%$ CI $=0.2445-0.9058)$. A highly statistically significant inverse correlation was found between serum magnesium and HbAlc levels $(\mathrm{r}=-0.4395, \mathrm{P}<0.0001)$ [Figure-2].

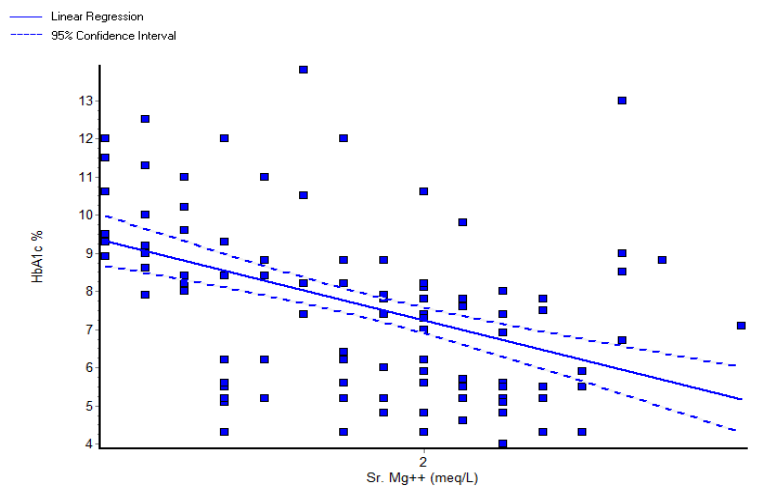

Figure 2 A highly statistically significant inverse correlation was found between serum magnesium and HbAlc levels $(\mathrm{r}=-0.4395, \mathrm{P}<0.0001)$.

$21 \%$ of patients with Insulin resistance (HOMA-IR $>2.6$ ) had hypomagnesaemia as compared to $12 \%$ of patients without Insulin resistance (HOMA-IR <2.6). The difference was extremely significant. ( $\mathrm{P}$ value $=<0.0001, \mathrm{RR}=0.1092,95 \%$ $\mathrm{CI}=0.6343-0.1879)$. A highly statistically significant inverse correlation was found between serum magnesium and HOMA-IR level $(\mathrm{r}=-0.6677, \mathrm{P}<0.0001)$ [Figure-3].

$7 \%$ of patients without Insulin resistance (QUICKI > 0.33) had hypomagnesaemia as compared to $22 \%$ of patients without Insulin resistance (QUICKI $<0.33)$. The difference was extremely significant. ( $\mathrm{P}$ value $=<0.0001, \mathrm{RR}=4.088$, $95 \%$ CI $=2.177-7.677)$. A highly statistically significant positive correlation was found between serum magnesium and QUICKI level $(\mathrm{r}=0.6036, \mathrm{P}<0.0001)$ [Figure-4].

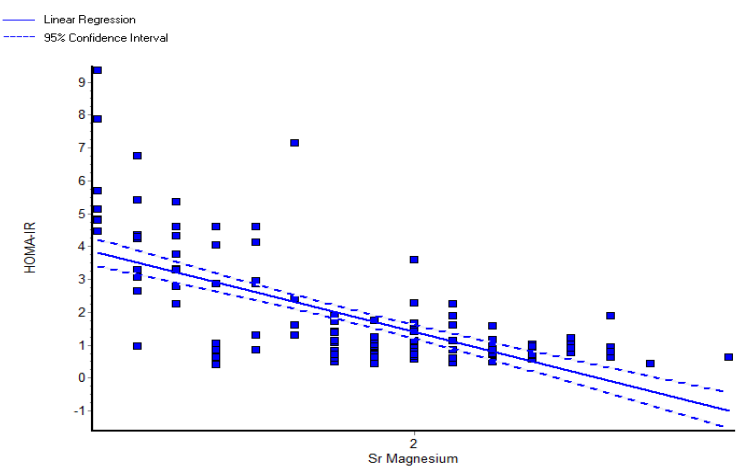

Figure 3 A highly statistically significant inverse correlation was found between serum magnesium and HOMA-IR level $(r=-0.6677, \mathrm{P}<$ $0.0001)$.

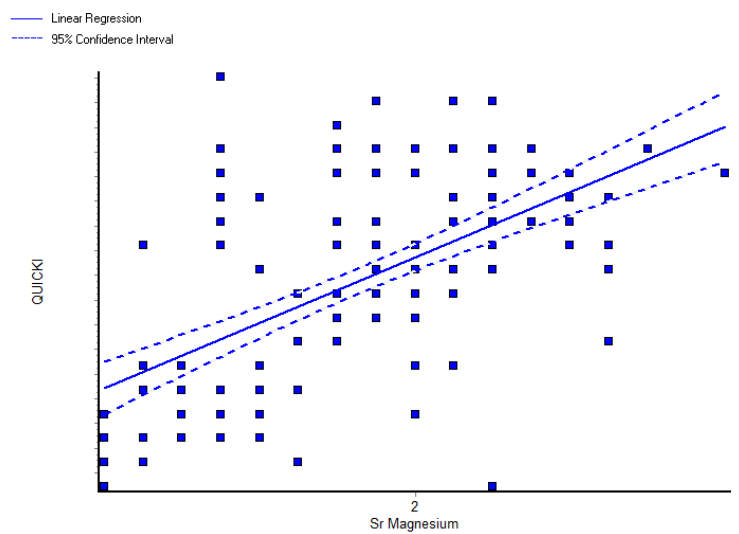

Figure 4 A highly statistically significant positive correlation was found between serum magnesium and QUICKI level $(\mathrm{r}=0.6036, \mathrm{P}<0.0001)$.

HOMA- $\beta$, indicator of $\beta$-cell function was significantly lower in cases as compared with controls. (42.115 \pm 21.612 vs $76.902 \pm 16.880)$ (P-value $<0.0005)$. However, a statistically non-significant correlation was found between serum magnesium and HOMA- $\beta(\mathrm{r}=0.03218, \mathrm{P}<0.6959)$ [Figure5].

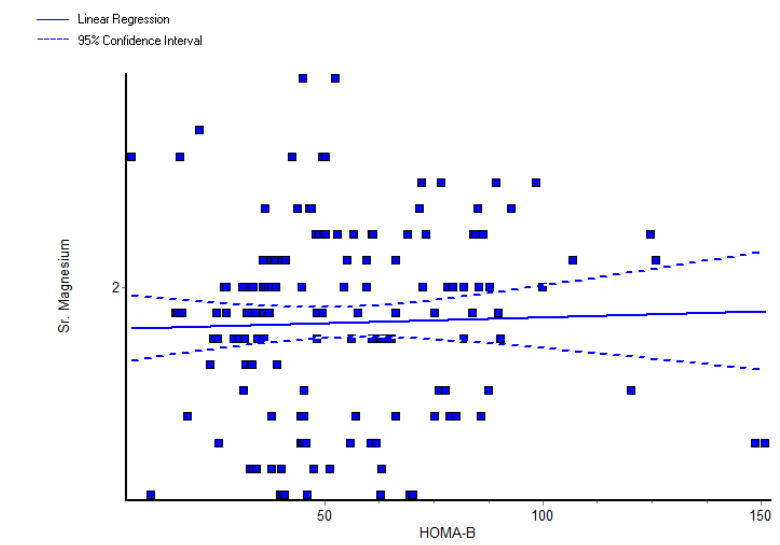

Figure 5 A statistically non-significant correlation was found between serum magnesium and HOMA- $\beta(\mathrm{r}=0.03218, \mathrm{P}<0.6959)$.

Also a highly statistically significant negative correlation was found between serum magnesium and fasting insulin level $(\mathrm{r}=-0.6911, \mathrm{P}<0.0001)$ [Figure-6]. From logistic regression analysis, fasting insulin levels was found to be an independent predictor of hypomagnesaemia. (odds ratio $0.651,95 \% \mathrm{CI}=$ 0.492 to 0.861 , and $\mathrm{P}$ value of 0.003 ) along with $\mathrm{HbA} 1 \mathrm{c}$ 
levels (odds ratio $6.087,95 \% \mathrm{CI}=1.025$ to 36.140 , and $\mathrm{P}$ value of 0.047 ) and duration of diabetes (odds ratio 0.502 , $95 \% \mathrm{CI}=0.261$ to 0.969 , and $\mathrm{P}$ value of 0.040$)$.

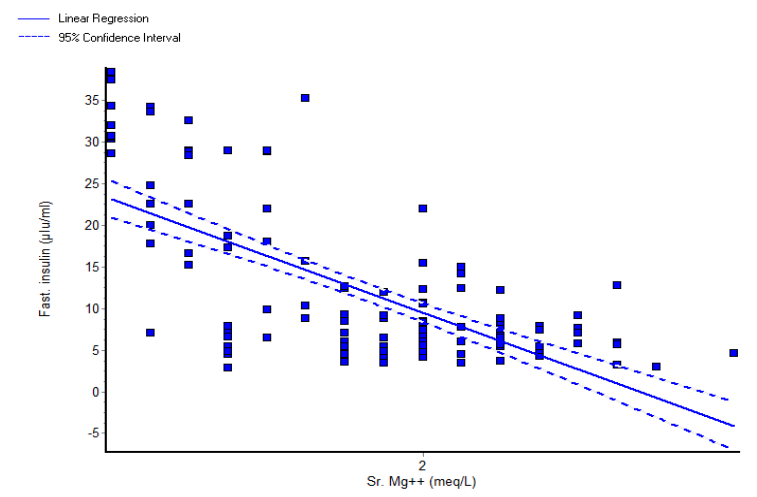

Figure 6 A highly statistically significant negative correlation was found between serum magnesium and fasting insulin level $(\mathrm{r}=-0.6911$, $\mathrm{P}<0.0001)$.

\section{DISCUSSION}

Prevalence of hypomagnesaemia was significantly more in diabetics $(34 \%)$ in our study and the prevalence increased with the duration of disease. Kulkarni et al ${ }^{[20]}$ reported the prevalence of hypomagnesaemia in diabetics at around $37 \%$ in his study.

Past history of hypertension and presence of diabetic retinopathy, had a significant positive correlation with hypomagnesaemia. Ischemic heart disease did not have any correlation with hypomagnesaemia. Studies by Antin et al ${ }^{[21]}$ was consistent with our observations but they did not find any significant correlation between hypomagnesaemia and hypertension. A highly statistically significant inverse correlation was found between $\mathrm{HbAlc}$ levels with serum magnesium levels in our study. Antin et al ${ }^{[21]}$ reported a higher prevalence of hypomagnesaemia with poor glycemic control but the correlation was statistically not significant.

A highly statistically significant inverse correlation was found between fasting insulin levels, HOMA-IR (marker of insulin resistance) with serum magnesium levels in our study. Asignificantly positive correlation was found between serum magnesium and QUICKI level (marker of insulin sensitivity). Observations made by Chutia et al ${ }^{[13]}$ corroborated with our findings. In our study, we found a statistically non-significant correlation was found between serum magnesium and HOMA- $\beta$, indicator of $ß$-cell function.

Our study revealed fasting insulin levels, duration of diabetes and $\mathrm{HbAlc}$ levels to be independent predictors for the development of hypomagnesaemia in cases with diabetes mellitus. Such an observation have not been reported by any other studies carried out in the past.

\section{Limitation}

The sample size of the study was small. A larger sample size would have created a better outlook towards the study end points. Intracellular magnesium has been found to be a better correlate with the development of insulin resistance than serum magnesium levels. Lack of facilities to determine intracellular magnesium in our hospital have prompted us to use serum magnesium for the study.

\section{CONCLUSION}

Our study highlights the importance of serum hypomagnesaemia in the development of insulin resistance and impaired glycemic status in patients with type 2 diabetes mellitus as compared to healthy controls. Replacement of magnesium to maintain normal serum levels might aid in better glycemic control and associated decrease in insulin resistance in diabetic patients. Further studies need to be done to establish this hypothesis.

\section{References}

1. Rude RK. Magnesium deficiency and diabetes mellitus. Causes and effects. Postgrad Med. 1992; 92(5):217-9.

2. Wälti MK, Zimmermann MB, Walczyk T, Spinas GA, Hurrell RF. Measurement of magnesium absorption and retention in type 2 diabetic patients with the use of stable isotopes. The American journal of clinical nutrition. 2003 Sep 1; 78(3):448-53.

3. Mcnair Pe, Christensen Ms, Christiansen C, Madsbad $\mathrm{S}$, Transbøl IB. Renal hypomagnesaemia in human diabetes mellitus: its relation to glucose homeostasis. European journal of clinical investigation. 1982 Feb 1; 12(1):81-5.

4. Ramadass S, Basu S, Srinivasan AR. SERUM magnesium levels as an indicator of status of Diabetes Mellitus type 2. Diabetes \& Metabolic Syndrome: Clinical Research \& Reviews. 2015 Mar 31;9(1):42-5.

5. Barbagallo M, Dominguez LJ. Magnesium and type 2 diabetes. World journal of diabetes. 2015 Aug 25;6(10):1152.

6. Paolisso GI, Ravussin ER. Intracellular magnesium and insulin resistance: results in Pima Indians and Caucasians. The Journal of Clinical Endocrinology \& Metabolism. 1995 Apr; 80(4):1382-5.

7. Kolterman OG, Gray RS, Griffin J, Burstein P, Insel J, Scarlett JA, Olefsky JM. Receptor and postreceptor defects contribute to the insulin resistance in noninsulin-dependent diabetes mellitus. Journal of Clinical Investigation. 1981 Oct; 68(4):957.

8. Paolisso G, Barbagallo M. Hypertension, diabetes mellitus, and insulin resistance: the role of intracellular magnesium. American journal of hypertension. 1997 Mar 31;10(3):346-55.

9. Isharwal S, Misra A, Wasir JS, Nigam P. Diet \& insulin resistance: a review \& Asian Indian perspective. Indian J Med Res. 2009; 129: 485-99.

10. Barbagallo $M$. Role of magnesium in insulin action, diabetes and cardio-metabolic syndrome X. MOL Aspects Med J. 2003;24(1-3):39-52.

11. American Diabetes Association.. Magnesium supplementation in the treatment of diabetes. American Diabetes Association. Diabetes Care. 1992;15(8):1065-7.

12. Dong JY, Xun P, He K, Qin LQ: Magnesium intake and risk of type 2 diabetes: meta-analysis of prospective cohort studies. Diabetes Care 2011,34(9):2116-2122

13. Chutia H, Lynrah KG. Association of serum magnesium deficiency with insulin resistance in Type 2 
diabetes mellitus. Journal of laboratory physicians. 2015 Jul;7(2):75.

14. Kulkarni AG, Shendge SK, VikramadityaShinde. Study of Serum Magnesium Levels in Types 2 Diabetes Mellitus. IOSR Journal of Dental and Medical Sciences (IOSR-JDMS). 2014; 13(4):115-9.

15. American Diabetes Association. Standards of medical care in diabetes-2015: summary of revisions. Diabetes care. 2015 Jan 1;38(Supplement 1):S4-.

16. Comparing the Original (HOMA1) and the Updated (HOMA2) Method: Evidence that HOMA2 Is More Reliable than HOMA1 http:/ / professional. diabetes.org/Abstracts_Display.aspx?CID $=54027$

17. Katz A, Nambi SS, Mather K, Baron AD, Follmann DA, Sullivan G, QuonMJ: Quantitative insulin sensitivity check index: a simple, accurate method for assessing insulin sensitivity in humans. $J$ ClinEndocrinolMetab. $2000 \mathrm{Jul} ; 85(7): 2402-10$
18. McAuley KA, Williams SM, Mann JI, Walker RJ, Lewis-Barned NJ, Temple LA, et al. Diagnosing insulin resistance in the general population. Diabetes Care. 2001;24:460-4.[PubMed]

19. Matsuda M, DeFronzo RA. Insulin sensitivity indices obtained from oral glucose tolerance testing: Comparison with the euglycemic insulin clamp. Diabetes Care.1999; 22:1462-70. [PubMed]

20. Kulkarni AG, Shendge SK, VikramadityaShinde. Study of Serum Magnesium Levels in Types 2 Diabetes Mellitus. IOSR Journal of Dental and Medical Sciences (IOSR-JDMS). 2014; 13(4):115-9.

21. Antin DS, Kashinkunti DM, Kataria AV, Dhananjaya M, Alevoor S. A cross sectional study of fasting serum magnesium levels in the patients with type 2 diabetes mellitus and Its relation to diabetic complications. Scholars Journal of Applied Medical Sciences (SJAMS) ISSN. 2014:2320-6691.

\section{How to cite this article:}

Siba Prasad Dalai et al (2017) ' Prevalence Of Hypomagnesaemia And Its Correlation With Insulin Resistance And Glycemic Status In Patients With Type 2 Dm', International Journal of Current Advanced Research, 06(04), pp. 3439-3443.

DOI: http://dx.doi.org/10.24327/ijcar.2017.3443.0288 